\title{
Emerging Nanomedicines for the Treatment of Atopic Dermatitis
}

\author{
Khushali Parekh, ${ }^{1}$ Tejal A Mehta, ${ }^{1,4}$ Namdev Dhas, ${ }^{1}$ Pavan Kumar, ${ }^{2}$ and Amirali Popat ${ }^{3}$
}

Received 15 October 2020; accepted 4 January 2021; published online 24 January 2021

\begin{abstract}
Globally, the prevalence of Atopic dermatitis (AD) is significantly increasing and affecting around $20 \%$ of population including children. Complex interactions amongst abnormality in epidermal barrier function, environment, infectious agents and immunological defects are considered as key factors in the pathogenesis of AD. Although the role of oxidative stress has been studied in some skin diseases, investigation of the same in $\mathrm{AD}$ is intermittent. Calcineurin inhibitors and/or topical corticosteroids are currently available; however, it causes atrophy of the skin, burning sensation, and systemic side effects which leads to poor patient compliance. These limitations provoke the strong need to develop an innovative approach in managing AD. Nanomaterials for effective drug delivery to skin conditions such as AD have attracted a lot of attention owing to its ability to encapsulate, protect, and release the cargo at the diseased skin site. However, there are lots of unmet challenges especially in terms of development of non-toxic formulations and clinical translation of established nanomedicines in the form of accessible products. Numerous formulations have emerged as carrier for poorly soluble and permeable drugs, viz., lipidic, polymeric, metal, silica, liposomes, hydrocarbon gels and this field is evolving. This review is intended to provide an insight incidences associated with pathophysiology of AD and challenges with existing treatments of AD. Focus is kept on reviewing current development and emerging nanomedicines for effective treatment of AD. The review also inculcates merits of several nanomedicines in overcoming challenges of existing products and its future implications.
\end{abstract}

KEY WORDS: nanomedicines; atopic dermatitis; topical drug delivery; skin targeting; novel formulations.

\section{INTRODUCTION}

Atopic dermatitis (AD) is a very common skin disease with chronic and relapsing immunological abnormalities in the skin $(1,2)$ characterized by recurrent eczematous lesions and intense itch. $\mathrm{AD}$ is a potentially enervating skin disease which demonstrates substantial socioeconomic influence on mankind worldwide (3). The phrase $\mathrm{AD}$ is a combination of two syndromes, i.e., atopy and dermatitis. Coca and Cooke invented the term "atopy" in 1923, which is directly related with IgEmediated reaction. Before the development of hypersensitivity reaction, there might be exposure to an allergen, although it involves a genetic component (4). Atopy can be present as asymptomatic sensation in any form of the

\footnotetext{
${ }^{1}$ Department of Pharmaceutics, Institute of Pharmacy, Nirma University, Ahmedabad, Gujarat 382481, India.

${ }^{2}$ Dr. Reddy's Laboratories Ltd., Hyderabad, India.

${ }^{3}$ School of Pharmacy, The University of Queensland, Woolloongabba, 4102, Australia.

${ }^{4}$ To whom correspondence should be addressed. (e-mail: tjshah3@gmail.com)
}

disease like $\mathrm{AD}$, fever, and asthma. Redness, swelling, and skin soreness are linked with the development of dermatitis. The presence of small blisters are observed due to direct irritation by an external allergen (5). AD is also known as "Prurigo Besnier (Besnier's itch) over the years, named after the French dermatologist Ernest Besnier (1831-1909)."

Distinctive symptoms of $\mathrm{AD}$ include mild to severe erythema, scaling, and excoriations to acute flare ups of eczematous pruritic lesions and intense itch (6). In $\mathrm{AD}$, skin becomes red, brownish, dry, scaly or cracked, and itchy due to decrease in the hydration of stratum corneum. This condition is mainly observed at night $(6,7)$. In infants, $\mathrm{AD}$ is manifested as an eczema associated with tiny bumps on the cheeks, where in the case of children and adults, it is observed often as rashes in the joint folds, on the rear part of the hands and often on the scalp (7). History of typical sequence of AD in the childhood indicates the initial step of the "atopic march" and often remits the chances of allergic disorder development in the later phase of life. This term is also known as "allergic march" (8). The prevalence of AD is increasing day by day, and literature shows rising number of patients suffering from AD during the past decade (9). Treatment of skin diseases 
using topical formulations is being accepted widely because very less concentration of the drug is absorbed systemically which ultimately reduces the side effects as compared to the conventional (parenteral or oral) drug administration. Currently available topical treatments have limited penetration into the deeper layers of the skin due altered skin condition during AD. This provoked the need to develop novel formulations with enhanced penetration into the deeper layers of the skin, i.e., epidermis, and provide more effective local drug release with low systemic toxicity. Moreover, the ability of the formulation to encapsulate various hydrophobic anti-inflammatory drugs is also considered a challenge especially when hydrophilic topical dosage forms are used in the treatment of atopic dermatitis. Therefore, a lot of efforts have been devoted in development of new carriers including nanoparticles for the treatment of AD. This review is aimed to provide an insight on incidences associated with pathophysiology of $\mathrm{AD}$ and challenges with existing treatments of AD. It also includes review of current development and emerging nanomedicines for effective treatment of AD.

\section{Epidemiology}

A study on distribution and regional variance in the occurrence of $\mathrm{AD}$ was performed internationally on 1 million subjects with three different phases (10). The prevalence of $\mathrm{AD}$ and the region where highest prevalence of $\mathrm{AD}$ is found vary continuously around the world. It was found that around $1 / 4^{\text {th }}$ of the world population is affected by $\mathrm{AD}$ during their lifespan. Between 1950 and 2000, the prevalence of AD increased approximately up to threefolds mainly in so called industrialized countries that it was referred as "allergic epidemic" $(6,11)$. However, eczema symptoms have been settled or reduced in some countries having huge prevalence. Nigeria, the UK, and New Zealand were the region of maximum prevalence previously; however, Latin America is now leading as most prevalent region for AD (12). Nevertheless, $\mathrm{AD}$ is a major health concern and the disease is still augmenting particularly in the developing world. During last few years, quite high occurrence of $\mathrm{AD}$ has been observed in India and it was the most common amongst children (13).

Natural history of AD suggests that almost $50 \%$ of influenced patients develop characteristic features within initial years of life and probably $95 \%$ experience an onset at the age below five (12). Around $75 \%$ with onset of AD early in the life have an extemporaneous retardation before adolescence, whereas the rest of $25 \%$ will continue experiencing a relapse of disease symptoms after few years with temporary recovery. Rare cause of exacerbations in AD may be food intake or contact with airborne allergens $(14,15)$. The chances of developing $\mathrm{AD}$ are more prominent in those having family history of occurrence of the disease. For example, if the cotwin is affected, the risk of the disease increases by $75 \%$ and $30 \%$ in the case of monozygotic and dizygotic twins respectively. This shows that susceptibility of AD has correlation with genetic factors $(16,17)$.

Increased prevalence of $\mathrm{AD}$ in the past few years has enforced a high socioeconomic burden in many developing countries in terms of medical management and patients' living standards. As a result, there has been an intensified interest in distinguishing environmental threats and precautionary measures (6).

According to the Global Burden of Disease survey 2010 conducted by The World Health Organization (WHO), AD was ranked first amongst common dermal diseases in terms of "life-years adjusted with disability" and "years lived with a disease" (8).

\section{Pathogenesis}

The researchers are unsure about the pathogenesis of AD for decades. There is still a lacuna in revealing consolidated proof of concept of AD. By elucidating the mechanism of occurrence of $\mathrm{AD}$ in inherently susceptible individuals, researchers have already achieved a salient milestone. Histology reveals the presence of eosinophils, macrophages, and $\mathrm{T}$ cells in the case of relapsing itch and inflammation (observed as overgrowth of dermis and epidermis) in AD (6). Pathophysiology of atopic dermatitis is described in Fig. 1.

Overall, multiple factors are affecting the development of AD which includes multifaceted interactions amongst ecological factors, defective epidermal barrier function, and susceptibility genes (19). The primary cause of AD is an abnormal skin barrier due to mechanical injury as a result of scratching which aggravates dry itchy skin. It is proven that the inherent and adaptive immune system interactions have a role to play in the AD pathological indications (20).

In recent years, the role of oxidative stress (OS) is being studied in the pathogenesis of AD. It is very well in knowledge that due to OS, genes coded for proinflammatory cytokines are up regulated which in turn promote tissue inflammation. Release of free radicals takes place from inflammatory cells when activated. From its prominent inflammatory compound, OS could be considered as one of the key role players in pathogenesis of AD (21). Factors influencing the pathogenesis of AD are described in Fig. 2.

Inflammatory lesions in AD are explained by two hypotheses: (i) imbalance in the adaptive immune system and (ii) abnormal skin barrier. The proposed two hypotheses may complement each other although they are not totally unrelated. Immunological Hypothesis. According to the theory of immunological inequity, it is claimed that imbalance of particularly $1,2,17$, and 22 type of $\mathrm{T}$ helper cell and regulatory T cells causes AD (19). In acute eczema, the state of allergic (atopic dermatitis) predominance of the naive $\mathrm{CD}^{+} \mathrm{T}$ cells as a result of $\mathrm{Th} 2$ differentiation is observed resulting into the enhancement in the generation of interleukins, viz., IL-4, IL5, and IL-13, which are responsible for improved levels of IgE. Correspondingly, inhibition of Th1 differentiation also takes place.

The Skin Barrier Hypothesis. According to this theory, reduced level of filaggrin and ceramides in the epidermis, a classical representation of inherited and acquired barrier function, is considered as the prime pathogenesis of $\mathrm{AD}$ (22-24). Normally, structural proteins of stratum corneum (SC) and stratum granulosum are encoded by filaggrin gene. This protein helps in binding the keratinocytes together and maintaining the integral skin barrier. It also plays role in stratum corneum hydration. With the faulty gene, filaggrin 


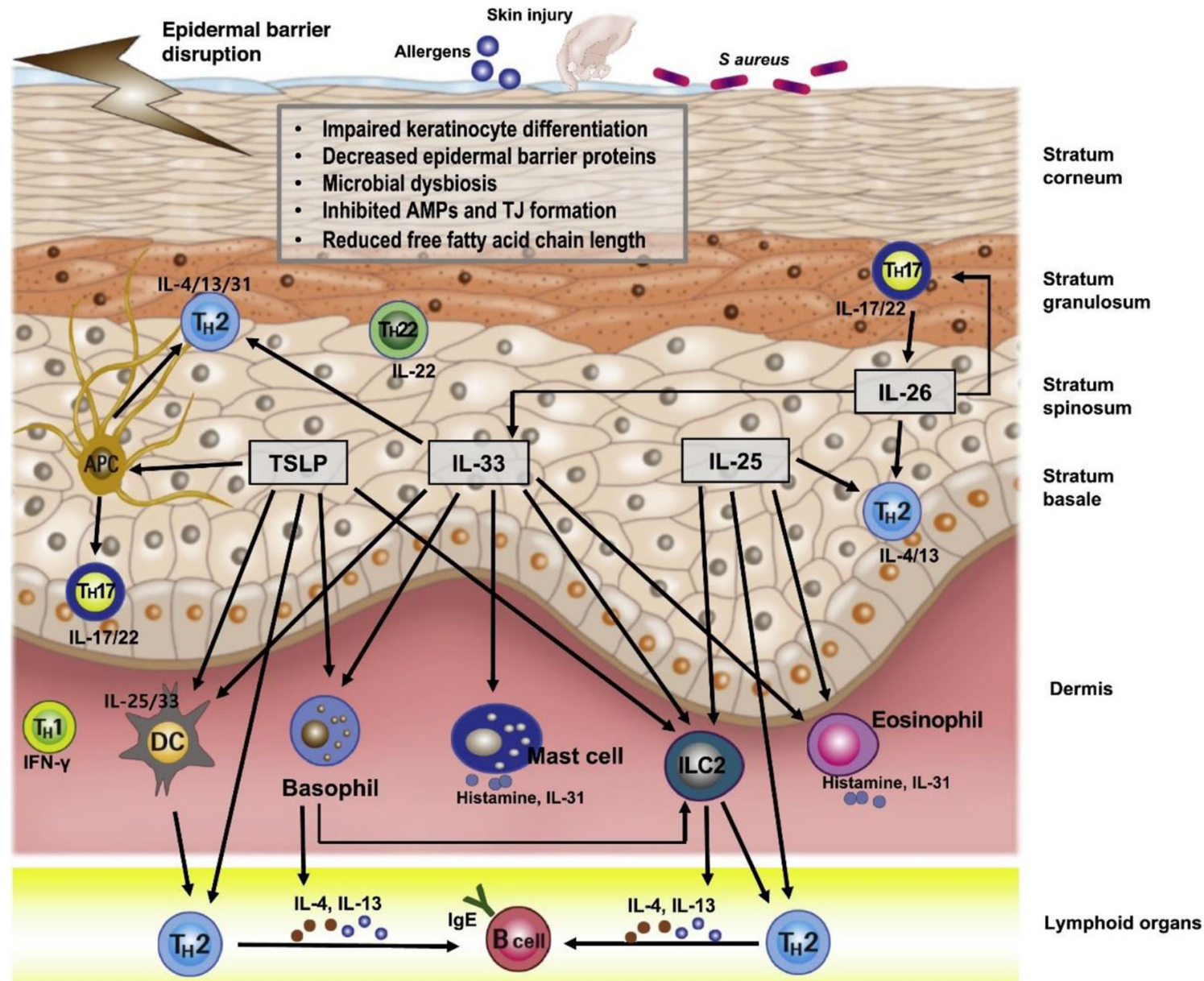

Fig. 1. Pathophysiology of atopic dermatitis [reproduced from reference (18)]

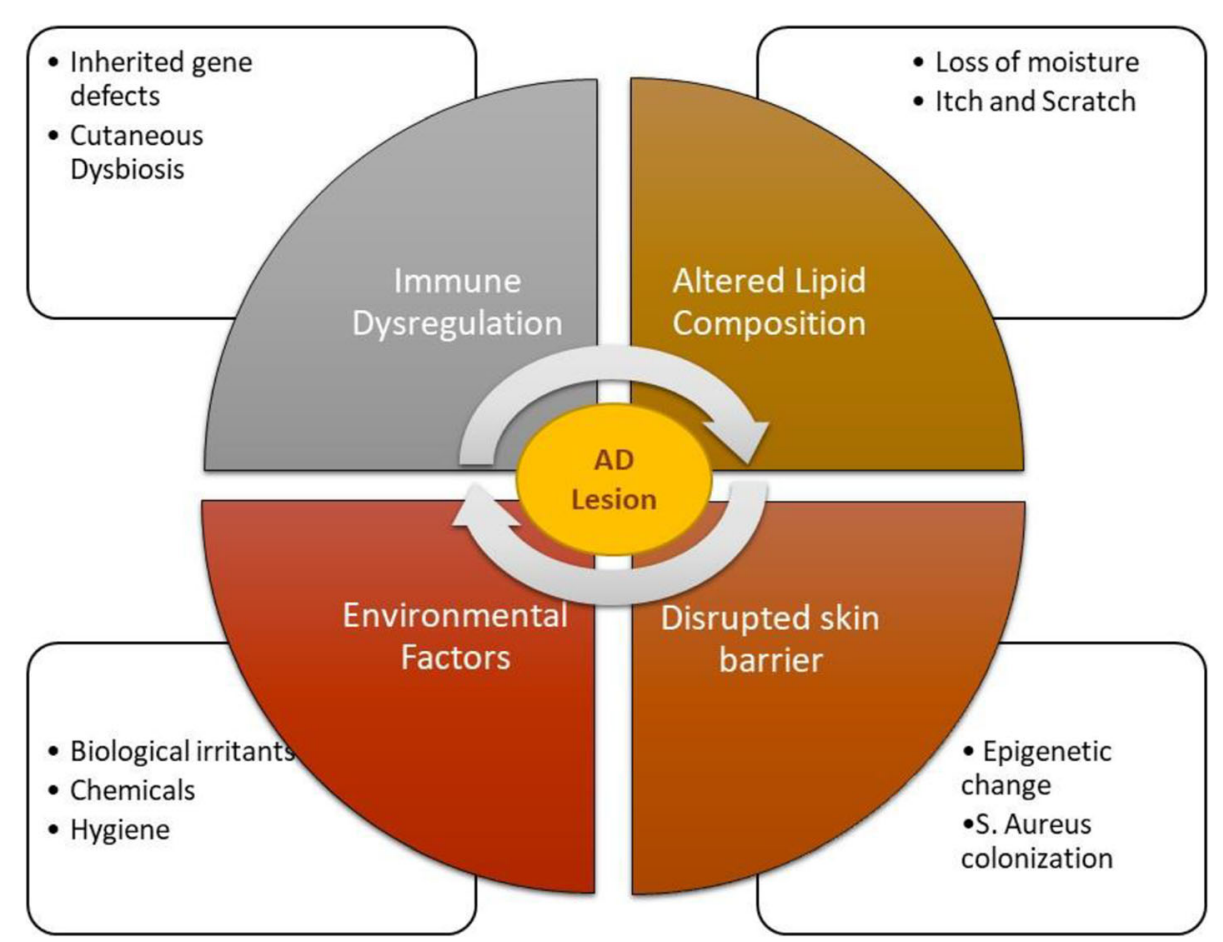

Fig. 2. Factors influencing the pathogenesis of atopic dermatitis 
production is reduced which leads to trans epidermal water loss (TEWL) and eczema. Barrier defects weaken the protective function of the epidermis against irritant substances responsible for aggravating the disease. Additionally, inhaled allergens penetrate into the epidermis due to retarded barrier function of SC and thereby they may contribute to aggravate $\mathrm{AD}(25,26)$.

Interestingly, in $\mathrm{AD}$, immunological imbalance and skin barrier abnormality present a cause and effect dilemma. Due to disturbed epidermal barrier function and dryness, skin becomes more susceptible for the internalization of numerous allergens and irritants into the skin along with other adverse environmental factors. This action triggers and provokes allergy with one more episode of inflammation $(27,28)$. Barrier integrity can be altered by inflammation itself. Therefore, dry skin is one of the most prominent factor in damaging the skin and also contributes in pathogenesis of AD (29). It could be said that barrier function restoration is essential while designing prevention plan and aggravation of AD (30).

\section{CURRENT STANDPOINT OF THE TREATMENTS FOR ATOPIC DERMATITIS}

Due to lack of complete cure of $\mathrm{AD}$; several patients experience a prolonged duration of the disease. The therapies include prevention of disease by reducing number of flares and reduction in relapse. Severity of flares are reduced by treatment with topical corticosteroids and/or topical calcineurin inhibitors.

The primary and secondary prevention includes delayed exposure to antigens. Food avoidance and prevention of AD have a direct relationship between them and its influence is still unclear (31); however, sensitization to food allergens is associated with infantile AD (32). Reports have shown that involvement of hydrolyzed or amino acid-based products in management of AD is significant (33).

Tertiary prevention can be achieved by diminishing the dryness of the skin, principally by means of daily utilization of skin-hydrating agents like cream or emollients. Care should be taken towards exposure to unknown irritants, like allergens and synthetic fiber-based clothing are avoided. Emollients do not have direct effect during eczema. Furthermore, skin dryness can be prevented by avoiding long, hot baths. Use of an emollient is endorsed for maintenance of hydrated epidermis and boost the function of epidermal barrier.

\section{Currently Available Formulations and their Limitations}

Many countries follow an agreement published as series of guidelines regarding the treatment of AD $(34,35)$. Guidelines are meant to help pediatricians and dermatologists in management of many patients with AD (36) which also contributes in improving their wellbeing. However, therapeutic management may get failed sometimes in patients with $\mathrm{AD}$, especially in the case of prolonged treatment. The main problems are socioeconomic complications, severity, and extent of activity of AD. It is thus expected that innovation in the treatment of AD will be essential. Table I covers currently available therapies for management and the treatment of the AD.

Currently, treatment of AD is managed by "reactive management" strategy which consists of combative response to acute flare-up incidents alongside topical agents falling in an anti-inflammatory category. However, acanthosis and perivascular lymphatic infiltration are seen histologically or as subclinical inflammatory change in the normal-appearing skin. Hence, normal-appearing skin is still a target for antiinflammatory drug. This treatment is further continued with another therapeutic treatment and use of anti-inflammatory drugs intermittently which is known as "proactive treatment." But these therapies may not be effective in all the patients (38).

Moreover, creams, ointments, and lotions like formulation contain oily vehicle and leave sticky residue on the skin. Bioavailability of drugs on the skin varies as skin is least perfused amongst all the tissues. Some secondary infection may be sub lying in the deeper layer of the skin and gives

Table I. Currently Available Conventional Dosage Forms for the Treatment of AD (37)

\begin{tabular}{|c|c|c|c|}
\hline Therapy & Drugs & Dosage form & Few brands \\
\hline \multirow[t]{8}{*}{ Corticosteroids } & Hydrocortisone & $\begin{array}{l}\text { L o t i o n / } \\
\text { o in tment/ } \\
\text { cream/tablet/ } \\
\text { injection }\end{array}$ & $\begin{array}{l}\text { Balneol HC, Beta } \\
\text { H C, Cortril, } \\
\text { Anus ol HC, } \\
\text { Hisone Tab, } \\
\text { Efcrolin, Licoid } \\
\text { lipo }\end{array}$ \\
\hline & Momentasone & $\begin{array}{l}\mathrm{L} \text { o t i o n / } \\
\mathrm{c} \mathrm{r} \mathrm{e} \mathrm{a} \mathrm{m} \mathrm{/} \\
\text { ointment }\end{array}$ & $\begin{array}{l}\text { Mom a te / M MF/ } \\
\text { Elocon/Cutizone }\end{array}$ \\
\hline & Triamcinolone & $\begin{array}{l}\text { Ointment/ } \\
\text { cream/lotion/ } \\
\text { gel/tablet/ } \\
\text { injection }\end{array}$ & $\begin{array}{l}\text { A r i s t o c o r t, } \\
\text { Aristogel, D-cort, } \\
\text { Ledecort, Cinalife }\end{array}$ \\
\hline & Prednicarbate & $\begin{array}{l}\text { Ointment/ } \\
\text { cream }\end{array}$ & $\begin{array}{l}\text { D e } \mathrm{r} \text { a } \mathrm{t} \text { o } \mathrm{p} / \\
\text { Prednicarbet } \\
\text { Dermatop E }\end{array}$ \\
\hline & Betamethasone & $\begin{array}{l}\mathrm{Cr} \text { e a m / } \\
\text { ointme nt/ } \\
\text { lotion }\end{array}$ & $\begin{array}{l}\text { A } 1 \mathrm{p} h \mathrm{~h} \mathrm{r} \mathrm{e}, \\
\mathrm{B} \text { e } \mathrm{t} \text { a } \mathrm{r} \mathrm{e}, \\
\mathrm{D} \text { e } \mathrm{t} \text { a } \mathrm{d} \text { e } \mathrm{m}, \\
\text { Celestone }\end{array}$ \\
\hline & Clobetasole & $\begin{array}{l}\text { L o t i o n / } \\
\text { shampoo/gel/ } \\
\text { c r e a m / } \\
\text { o intme nt/ } \\
\text { solution }\end{array}$ & $\begin{array}{l}\text { Clobex, Cormax, } \\
\text { Embelline, Impoyz }\end{array}$ \\
\hline & Fluticasone & $\begin{array}{l}\text { Ointment/ } \\
\text { cream/lotion }\end{array}$ & $\begin{array}{l}\text { Cutivate/Zoflut/ } \\
\text { Molidem/Flutilab }\end{array}$ \\
\hline & Dexamethasone & $\begin{array}{l}\text { Gel/cream/ } \\
\text { o in t m e n t } \\
\text { solution }\end{array}$ & $\begin{array}{l}\mathrm{D} \text { e } \mathrm{c} \text { a } \mathrm{d} \text { e } \mathrm{r} \mathrm{m} \\
\text { Decadorn, Dexair }\end{array}$ \\
\hline \multirow[t]{2}{*}{$\begin{array}{l}\text { Calcine urin } \\
\text { Inhibitors }\end{array}$} & Tacrolimus & $\begin{array}{l}\text { Ointment/ } \\
\text { cream/lotion/ } \\
\mathrm{t} \text { a b l e t/ } \\
\text { capsule }\end{array}$ & $\begin{array}{l}\text { Protopic, Topgrap, } \\
\text { Olm is Forte, } \\
\text { Tacrel, Crolim, } \\
\text { Olmis, Tacrograf }\end{array}$ \\
\hline & Pimecrolimus & Cream & Elidel, Pacroma \\
\hline Phototherapy & UV light & - & - \\
\hline
\end{tabular}


false symptomatic relief on the skin. Targeting deeper layer of the skin is also difficult due to protective barrier. Also, issue of poor penetration of the drug in the skin persists with the diseased condition.

\section{Ongoing Clinical Trials}

Although there are limitations with currently available therapies, they are treating the disease in current scenario. Research have been done for incorporation of various new molecules in the conventional dosage forms. Table II comprises of few clinical trials being done with different molecules for more effective treatment of $\mathrm{AD}$. If these products pass the clinical trials successfully, many products with better effectiveness will acquire the market in near future.

Issues associated with currently available treatments indicate a compelling need for the development of novel formulations which can overcome the shortcomings of conventional therapies. In the following sections, we have reviewed nanomedicine as one of the emerging technologies for improving drug delivery to skin with a particular focus on AD.

\section{NANOMEDICINES FOR ATOPIC DERMATITIS-CURRENT SCENARIO}

Topical corticosteroids are considered as the first-line treatment of AD. They have anti-inflammatory and antiproliferative actions which are responsible for their therapeutic effect as well as side effects like skin atrophy (skin thinning), telangiectasia, and skin burning. Topical steroids inhibits the enzyme phospholipase A2 by synthesizing lipocortin. Inflammation is caused when phospholipase A2 release arachidonic acid from the cell membrane. The inhibition of phospholipase A2 results in the reduction of inflammation. This inhibitory actions affect the keratinocyte proliferation, fibroblasts, and hyaluronan synthase 3 enzyme resulting in the reduction of hyaluronic acid in the extracellular matrix leading to dermal atrophy. These side effects are associated with long-term use of topical steroids (40). Hence, these agents are suitable to use for short-term therapy only $(35,41)$. The growth of nano-intervention-based drug delivery is rapidly growing along with impending applications in healthcare and drug nanoplatform-based delivery sector. The skin provides inherent protection against entry of foreign particles, although therapeutic NPs can be delivered in affected areas of the skin via hair follicle openings. Potential of NP-based drug delivery needs to be understood deeply although it has been publicized as a facilitating technology in the treatment of local diseases. Mechanisms related to the explanation of infiltration and preservation of NPs across the epidermal barrier have been thoroughly discussed. One study result suggests that rate of drug release in the dermal layers may be controlled by incorporating the drug NP into the lipid matrix to achieve therapeutic efficacy (42). There are several distinct properties of nanoparticles, viz., surface properties, charge, shape, and size, that can affect the release rate and skin penetration. Furthermore, when NPs are delivered topically, they are expected to retain in the skin. Hence, the study of degree and rate of infiltration of NPs is important to
Table II. Details of Clinical Trials Being Done for the Treatment of Atopic Dermatitis (39)

\begin{tabular}{llll}
\hline Molecule & $\begin{array}{l}\text { S t u d y } \\
\text { population }\end{array}$ & Phase & Status \\
\hline
\end{tabular}

ZEP-3Na (0.1\% 5-75 years old NCT04307862, Ongoing

or $1 \%) \quad$ with mild to Phase II moderate $\mathrm{AD}$

Ultra Violet A 6--16-year-old NCT04444726, Recruiting device.+ topical children not applicable

betamethasone

dipropionate

$0.05 \%$

Antroquinonol 20-65 years NCT04110873, Terminated (It capsule $50 \mathrm{mg}$ o ld wi t h phase II was hard to find and $100 \mathrm{mg}$ moderate to suitable subject severe AD due to strict e n roll me n t criteria.)

PF 0496584212 to $<18$ NCT03796676, Completed ( J A K 1 years old with phase III inhibitor) moderate to severe AD

Diluted sodium 8-65 years old NCT02594969, Completed hypochlorite with healthy not applicable

solution and skin or having moisturizers AD

Crisaborole 2\% 7 months and NCT04498403, Ongoing

ointment older with phase III

$\mathrm{mild}$ t o moderate $\mathrm{AD}$

B a ricitinib 18 years and NCT03733301, Completed (LY3009104) in older with phase III

combination moderate to

with corticoste- severe $\mathrm{AD}$

roid

Upadacitinib 12-75 years NCT04195698, Recruiting

o $1 \mathrm{~d}$ w i t h phase III

moderate to

severe $\mathrm{AD}$

Thykamine) 18 years and NCT03540043, Terminated $0.05 \%, 0.25 \%$, older with phase II ( R e a c h e d and $0.1 \% \quad \mathrm{~m} \mathrm{i} \mathrm{l} \mathrm{d} \mathrm{t} \mathrm{o} \quad \mathrm{r}$ e q u i r e d moderate $\mathrm{AD} \quad \mathrm{an}$ a ly z a ble sample size; COVID-19 recruitment challenges)

Secukinumab 18 years and NCT02594098, Completed

$300 \quad \mathrm{~m} g$ older with phase II

subcutaneous chronic AD (>

injection 6 months)

Lebrikizumab 18 years and NCT03443024, Completed

subcutaneous older with phase II

injection moderate to

severe atopic

dermatitis

0. $5 \% \quad 18$ to 65 years NCT01856764, Completed

Roflumilast o ld with phase II

cream moderately

severe AD

lesion

DS-2741a 20 years and NCT04211415, Active, not older phase I recruiting 
get idea about the interactions of NPs with physiological fluids and thereby their entry into the systemic circulation (43). Figure 3 is a representation of various mechanisms by which NPs are delivered to the skin. Solid lipid nanoparticles (SLN), nanolipid carriers (NLCs) (44), and nanoemulsions and microemulsions (45) are few lipid-based systems which have been explored for topical drug delivery. Other than these systems, polymeric nanoparticles and liposomes have also been explored as an alternative drug delivery system for topical route $(46,47)$.

\section{Polymer-Based Nanoparticles}

Polymeric NPs have various characteristic features such as biodegradability, biocompatibility, low particle size, and greater surface charge for stability which are attractive for its use for topical delivery. More specifically, polymeric NPs have been used with several drugs for the treatment of AD, owing to their exceptional properties such as greater entrapment efficiency and sustained release, physiological stimuliresponsive nature, enzymatic degradation prevention, and targeting specific site which minimize off targeting effects.

For instance, Zhuo et al. (49) fabricated hyaluronic aciddecorated tacrolimus-loaded chitosan NPs (HA@TCLCSNPs) with aim to maximize the dermal targeting and enhance anti-dermatitis efficiency. The results indicated that particle size, zeta potential, and entrapment efficiency (\%EE) of optimized TCL-CSNPs were found to be $156 \mathrm{~nm},+53 \mathrm{mV}$, and $84.11 \%$, respectively. The surface charge, average particle size, and entrapment efficiency (\%EE) of optimized HA@TCL-CSNPs were found to be $216 \mathrm{~nm},+34 \mathrm{mV}$, and $57.14 \%$, respectively. The size was increased due to coating of HA onto the CSNPs, whereas zeta potential decreased due to the negatively charged HA. Furthermore, the release study confirmed that after $8 \mathrm{~h}$, TCL-CSNPs and HA@TCL-CSNPs showed $75 \%$ and $25 \%$ of drug release. This phenomenon occurred owing to the presence of HA as HA prevents or acts as a barrier for the release of TCL. Additionally, HA may restrict the diffusion of water into the polymer matrix which consequently retards the release rate of TCL. Additionally, HA@TCL-CSNPs demonstrated greater efficiency in the maintenance of intact skin throughout the period of induction and treatment and displayed minimum symptoms of erythema and dryness as compared to TCL-CSNPs. It may be owing to the optimal localization of TCL into dermis and epidermis. Histopathological study demonstrated that HA@TCL-CSNPs restored the skin integrity in the mice and found to be safe.

In the similar manner, Pandey et al. (50) formulated HAcoated betamethasone valerate (BMV)-loaded CSNPs (HA@BMV-CSNPs) for dermal targeting and enhance penetration across the stratum corneum. The results indicated that particle size, zeta potential, and \%EE of optimized HA@BMV-CSNPs were found to be less than $300 \mathrm{~nm},+58$ $\mathrm{mV}$, and $86 \%$, respectively. The in vitro release investigation demonstrated that HA@BMV-CSNPs showed Fickian diffusion-type release mechanism in simulated skin surface ( $\mathrm{pH}$ 5.5). The permeation study concluded that as compared to HA@BMV-CSNPs, BMV from BMV-CSNPs was significantly permeated through the skin. However, more dermal retention was observed for BMV in the case of HA@BMV-
CSNPs as compared to BMV-CSNPs. Furthermore, Try et al. (51) studied the effect of size of NPs on skin penetration in dermatitis models such as porcine and murine. For the same, the researchers developed PLGA NPs with two different sizes, i.e., $70 \mathrm{~nm}$ and $300 \mathrm{~nm}$. The results indicated that no skin penetration was found in the case of healthy skin. However, PLGA NPs with particle size of $70 \mathrm{~nm}$ was significantly accumulated higher (15-folds in mice and fivefolds in pig) in the inflamed skin as compared to PLGA NPs with $300 \mathrm{~nm}$ of size. Additionally, penetration depth study revealed that in pig skin model, PLGA NPs with $70 \mathrm{~nm}$ size were found to be greatly penetrated $(46 \mu \mathrm{m})$ as compared to PLGA NPs with particle size of $300 \mathrm{~nm} \mathrm{(23}$ $\mu \mathrm{m})$. However, in mice skin, both size of PLGA NPs demonstrated similar penetration depth $55 \mu \mathrm{m}$, but the penetration depth of NPs decreased over the time in mice to $20 \mu \mathrm{m}$.

Moreover, Siddique et al. (52) developed a cream containing hydroxytyrosol (HT) and hydrocortisone (HC)loaded CSNPs for safe and tolerable efficacy of NPs in potential treatment of AD. The results revealed that optimized size of HC/HT CSNPs was less than $250 \mathrm{~nm}$ and cream of $\mathrm{HC} / \mathrm{HT}$ CSNPs was found to be stable when stored at $25^{\circ} \mathrm{C}$. Furthermore, erythema intensity transepidermal water loss (TEWL) for 28-day application did not display any signs of redness, local irritation, and toxicity. In addition to this, the similar results were obtained for biochemistry of blood, blood hematology, and adrenal cortico-thyroid hormone level at 0 and 28 days. Thus, from the aforementioned results, it can be concluded that $\mathrm{HC} / \mathrm{HT}$ CSNP cream is safe and well tolerated, which can be beneficial in the treatment of AD. Furthermore, considering the stimuli-responsive delivery system can be an effective platform for dermal application.

Sahle et al. (53) fabricated various types of $\mathrm{pH}$ responsive dexamethasone-loaded Eudragit $\AA^{\circ}$ L 100, Eudragit ${ }^{\circledR}$ L 100-55, Eudragit $\AA$ S 100, HPMCP-50, HPMCP-55, and cellulose acetate phthalate NPs and fabricated using nanoprecipitation method (54). The results indicated that cellulose acetate phthalate NPs were found to be more $\mathrm{pH}$ responsive as compared to other NPs. Cellulose acetate phthalate NPs when dissolved in $10 \mathrm{mM}$ pH 7.5 buffer found that greater than $80 \%$ of the drug was released within 7 $\mathrm{h}$, whereas acrylate NPs when dissolved in $40 \mathrm{mM} \mathrm{pH} 7.5$ buffer found that $65-70 \%$ of the drug was released after $7 \mathrm{~h}$. The study also concluded that properties of NPs and their release pattern can be modulated by blending various polymers and all formulations were found to be safe.

Additionally, Katas et al. (55) investigated for histological stabilization and immune-modulatory effects of $\mathrm{HT} / \mathrm{HC}$ co-loaded CSNPs via transcutaneously using NC/Nga mouse model. The ex vivo study confirmed that skin thickness of AD-induced CSNP-treated mice $(456 \mu \mathrm{m})$ was significantly reduced as compared to atopic mice $(916 \mu \mathrm{m})$. Immune spectrum analysis revealed that HT/HC CSNPs were capable of restraining immunoglobulin $\mathrm{E}$ ( $\mathrm{IgE})$, histamine, $\mathrm{T}$ helper cells $\left(\mathrm{T}_{\mathrm{H} 1} / \mathrm{T}_{\mathrm{H} 2}\right), \mathrm{VEGF}-\alpha$, and prostaglandin $\mathrm{E} 2\left(\mathrm{PGE}_{2}\right)$ producing cytokines in serum and skin biopsies of tested mice. In the similar manner, Hussain again investigated the downregulation of immunological mediators using HC-loaded CSNPs in 2,4-dinitrofluorobenzene-induced AD-like skin lesion. The analysis of expression of cytokine in AD-like skin 
a

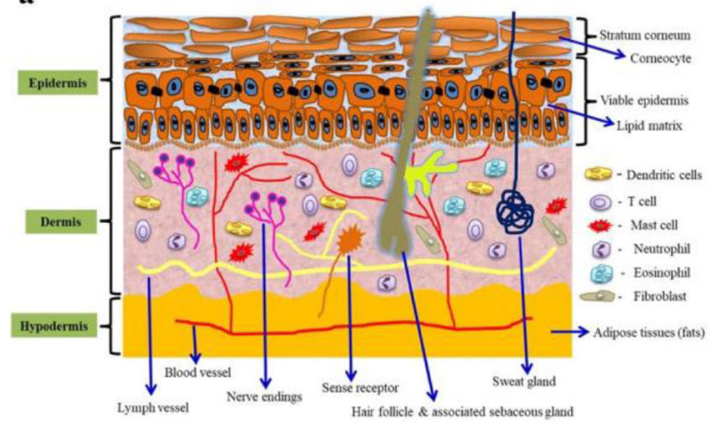

b

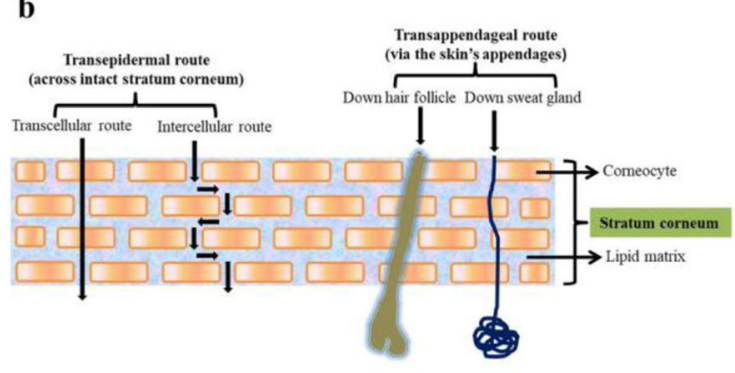

Fig. 3. Various mechanisms for dermal delivery of NPs. a Anatomy of the skin and $\mathbf{b}$ routes of drug penetration (reproduced from reference (48))

lesion indicated that HC CSNPs inhibited the pathological expression of TNF- $\alpha$, interferon- $\gamma$, IL-4, IL-5, IL-6, IL-12p70, and IL-13. Additionally, histological study demonstrated that HC CSNPs inhibited fragmentation of elastic fibers and fibroblast infiltration.

Yu et al. (56) explored the development of a hybrid skintargeting nano system with nicotinamide (NIC) and chitosan NP (CS@NP) for encapsulating Tacrolimus (FK506), i.e., FK506@NIC@CSNP, for the treatment of dermatitis. Results showed that FK506 containing NIC@CSNP has significantly enhanced penetration and deposition into the skin as compared to Protopic $\AA$. The results of efficacy studies of the clinical symptoms in animal model of AD demonstrated that approximately $1 / 3^{\text {rd }}$ dose of NIC@CSNP was superior to that of Protopic alone. The adjuvant therapeutic response and anti-AD effects to moderate level were observed with NICCS-NP vehicle. Ghosh et al. (57) studied the efficacy of guar gum nanoparticles (GN) in $\mathrm{AD}$ on BALB/c mice. Diseaseinduced mice were treated topically with GN. Ear thickness was found significantly reduced on the 28th day. After the application of GN on the skin, the total cell count, eosinophil count, and Th cell and macrophage populations were decreased and the same was confirmed by histological studies. Cellular infiltration and epidermal thickness were reduced in ear tissue after the treatment. Efficacy enhancement of hydrocortisone acetate was studied in synthetic polymeric nanoparticles. Rosado et al. used solvent displacement method in preparation of the hydrocortisone acetate (HCA)-loaded poly ( $\varepsilon$-caprolactone (PCL) nanoparticles (NPs) to achieve a prolonged release of drug and reduction of side effects. It was confirmed that the developed formulation indicated minimum side effects and increased its therapeutic efficacy (58).

\section{Lipid-Based Nanoparticles}

It has been known for a long time that lipid-based NPs such as solid lipid NPs (SLNPs) and nanostructured lipid carriers (NLCs) have been extensively studied by the researchers for topical delivery, owing to their ability to load both hydrophilic and/or lipophilic therapeutic moieties (44). Additionally, the carriers mimicking physiological lipids have been attracted lot of researchers owing to their higher biocompatibility, biodegradability, and follicle delivery. They have the capability to release the drug in a controlled manner and provide greater occlusion which in turn is responsible for improved skin hydration (59). However, NLCs are far better than SLNs as it overcomes the disadvantages of SLNs such as leaking of drug/therapeutic moiety during storage caused by lipid polymorphism, risk of gelation, and limited drug loading (60). NLCs are formed by utilizing solid lipid and liquid lipid which ultimately forms the less perfect crystalline structure with many imperfections providing more space for drug accommodation $(61,62)$. Many studies came to conclusion that small-size lipid carrier ensures close contact to the stratum corneum and can improve penetration of therapeutic moiety into the skin $(63,64)$. The epidermal targeting may be exploited using NLCs and SLNs as well as reduction of side effects can be achieved. Potential side effects due to systemic absorption of topical corticosteroids (atrophy, skin thinning) can also be eliminated using such carriers. SLNs have also demonstrated to facilitate therapeutic moiety retention in the upper layer of skin and to obtain occlusion, which occurs owing to the strong adhesion properties of nanocarrier and small size, leading to the formation of the film on the skin and reduce the TEWL by helping in restoration of the physical barrier (65).

Pople and Singh (30) explored the high-pressure homogenization technique in the development of tacrolimus-loaded modified NLC (T-MNLC) with an aim to enhance its solubility. They used lipophilic solubilizer in carrier lipid matrix for drug delivery to the skin. T-MNLC formulation was found stable with reduced total lipid concentration in carrier. Thus, the study highlighted that novel T-MNLC prepared using lipophilic solubilizers were very useful in terms of performance, and improved stability and skin retention. Pople and Singh also studied the skin hydration properties, targeted delivery, therapeutic effectiveness, and toxicity of modified nanolipid carrier. The enhanced targeting and therapeutic efficacy were studied on in vivo model for AD-like skin lesions in BALB/c mice. Moreover, improved safety was observed with T-MNLC-treated group. Thus, it indicates that novel T-MNLC formulation would get wide acceptance by the patients to treat large skin areas of $\mathrm{AD}$ with chronic treatment regimen (66).

Maia et al. (67) investigated SLN to increase targeting to the viable epidermis. SLN of a topical glucocorticoid prednicarbate (PC) were developed which penetrates almost $30 \%$ greater into human skin as compared to PC cream. This may possibly because of particle size and close interaction of SLNs with the stratum corneum. Biotransformation of PC did not change by SLN incorporation and the same was 
confirmed by penetration study of prednicarbate PC-SLNs. A threefold increase in PC permeation after incorporation into SLNs was reported.

Fang et al. (68) proposed use of betamethasone dipropionate (BD)-loaded NLCs (BD-NLC) in topical ointment formulation for the treatment of $\mathrm{AD}$. In vitro drug release results of BD-NLC suggest better skin localization using without ointment. No evidence of skin irritation was observed during in vivo studies using rabbits. Moreover, the self-made topical ointment exhibited required drug retention in skin tissue of living mice. This study accentuated the development of BD-NLC as a potential therapy with reduction in adverse effects induced by systemic absorption.

Elastic liposomes were developed for taxifolin glycoside (TXG) to be delivered to the skin. Pep-1 peptides were exposed to thiolmaleimide reaction for conjugation to drug containing elastic liposome. Prepared formulation was examined for efficacy and skin permeation. Hence, TXG-loaded Pep1-EL preparations can be considered as effective measure for the treatment of AD (69). Nanonization is one of the approaches to improve solubility; hence, nanomedicines are most explored for hydrophobic drugs. Lipid-based nanoformulations are widely explored as compared to other approaches and due to high affinity of the lipids with skin. These formulations have proven to be more promising.

\section{Micro-nano Emulsions}

Emulsion-based systems are obtained using two or more immiscible liquids, where one is dispersed phase, and another is dispersion medium. Emulsion-based systems possess certain merits such as ease of scale-up with cost effectiveness and ease of formation and sterilization. However, some disadvantages of this method are complex and time-consuming development process, phase inversion, drug leakage, and surfactant-/co-surfactant-related toxicity. It has an ability to incorporate and enhance penetration of both hydrophilic and/ or lipophilic therapeutic moieties. Therapeutic moieties having higher solubility are categorized to this performance as they enhance the concentration gradient towards the skin. Mechanism of surfactant within the vehicle is penetration enhancer as well as internal mobility modulator also contributes to the effective performance of emulsion in skin delivery. The release of therapeutic moiety from the emulsion depends on the interaction between surfactant and therapeutic moiety or/and partitioning of therapeutic moiety in water and oil phase. In the view to above discussion, Baspinar et al. (70) developed positively charged prednicarbate nanoemulsion with physical and chemical stability for the treatment of AD. Use of positively charged carrier is helpful in dermal delivery, as adsorption of the same onto the negatively charged skin. This increases the retention time and thus the availability of the drug at targeted region. A microemulsion cream formulation of tacrolimus was developed and compared against ointment in hapten-induced murine model of dermatitis which enhanced the penetration through skin. The penetration enhancement was consigned to the possibility of dose reduction. The results of developed cream was confirmed by in vivo studies and it was found that the formulation significantly reduces expression of cytokine by more deposition in the targeted site (71).
Alam et al. (72) developed the clobetasol propionate (CP) topical oil-in-water $(\mathrm{o} / \mathrm{w})$ nanoemulsion using aqueous phase titration method. Anti-inflammatory activity of $\mathrm{CP}$ loaded nanoemulsion was improved. There was a significant increase in nucleoside triphosphate diphosphohydrolases activity in lymphocytes. Use of high amount of surfactant was proven safe by skin irritation studies on animal model and hence proved safe for human use.

Yang et al. (73) did comparative studies of triptolide (TPL) nanoemulsions and nanoemulsion-based gel of TPL to check their effect on percutaneous permeation enhancement. TPL nanoemulsion gels and TPL nanoemulsion showed better penetration as compared to TPL gels in in vitro studies. Greater AUC was observed with TLP nanoemulsion as compared to TLP gels during in vivo microdialysis. Dermatitis and eczema symptoms were significantly reduced with TPL nanoemulsion gels and can reduce IFN- $\gamma$ and IL-4 expressions. Obtained results confirm the suitability of nanoemulsion gel as a promising percutaneous carrier to provide low toxicity and prolonged release transdermal formulation for the clinical treatment of $\mathrm{AD}$ and eczema.

\section{Nanosuspension}

Romero et al. (74) developed a nanosuspension containing cylosporin A (CyA) with the aim to increase dermal penetration. They used wet bead milling technique for the preparation of amorphous nanoparticles. CyA in concentration of $5 \% \mathrm{w} / \mathrm{v}$ was dispersed in water and vitamin $\mathrm{E}$ polyethylene glycol succinate (TPGS, Kolliphor TPGS) was added to that dispersion. Average particle size was around $350 \mathrm{~nm}$ and $\mathrm{D}_{99}$ (laser diffraction diameter 99\%) was $690 \mathrm{~nm}$. Upon storage at room temperature, the suspension was retaining amorphous state for almost 1 year. Hence, it was concluded that the prepared nanosuspension was physically stable. There was reduction of $5 \%$ in the total drug content over the span of 1 year but that might be because of a large surface area in contact with water. From that, it was considered that the formulation is feasible as commercial product with expiry date. Micron-sized powder and nanoparticles of CyA were incorporated into HPC gels. Both the formulations were evaluated for penetration and drug retention using fresh pig ear skin, applying the tape stripping method. Micron-sized drug powder showed $71.3 \mu \mathrm{g} / \mathrm{cm}^{2}$ and nanoparticles of CyA showed $450.1 \mu \mathrm{g} / \mathrm{cm}^{2}$ which is 6.3 times higher penetration. From the studies on CyA amorphous nanoparticles, dermal nanomedicines delivery seems feasible.

Other than the above discussed formulations, many researchers have worked on the usefulness of different nanomedicines in the topical drug delivery system. They have explored various approaches in the preparation method and delivery systems. Recent development in nanoformulations in the treatment of Atopic dermatitis is summarized in Table III along with advantages of developed formulation by various researchers and few findings are discussed as following.

\section{EMERGING NANOMATERIALS FOR THE TREATMENT OF AD}

Nanoformulations discussed above have the potential to deliver the therapeutic agents topically for the treatment of 
Table III. Example of Nanoformulations for the Treatment of Atopic Dermatitis

\begin{tabular}{|c|c|c|c|}
\hline \multicolumn{2}{|c|}{ Type of nanoformulation } & Active & Conclusion/novelty \\
\hline \multicolumn{2}{|l|}{ Nanocrystal } & $\begin{array}{l}\text { Dexamethasone (75) } \\
\text { Sirolimus (76) }\end{array}$ & $\begin{array}{l}\text { - Crystals are made up of } 100 \% \text { pure drug and } \\
\text { reduced excipient incompatibility } \\
\text { - Easily scalable } \\
\text { - Stable formulation } \\
\text { - Improves solubility of poorly water-soluble drug. } \\
\text { - Higher penetration as compared to micronized } \\
\text { powder }\end{array}$ \\
\hline \multicolumn{2}{|l|}{ Nanoemulsion } & $\begin{array}{l}\text { Triptolide }(73) \text {, clobetasol propionate }(72) \text {, } \\
\text { prednicarbate }(70) \text {, plaunoi extract }(33,35)\end{array}$ & $\begin{array}{l}\text { - Better penetration compared to the conventional } \\
\text { topical formulation } \\
\text { - Thermodynamically stable } \\
\text { - Spontaneous emulsification }\end{array}$ \\
\hline \multirow[t]{3}{*}{ Nanoparticles } & Polymeric & $\begin{array}{l}\text { Tacrolimus (56) } \\
\text { Guar gum (57) } \\
\text { Hydrocortisone acetate (58) } \\
\text { Clobetasol } \\
\text { Quercetin (47) }\end{array}$ & $\begin{array}{l}\text { - Stabilization of compound by physical and } \\
\text { chemical protection. } \\
\text { - Enhanced retention and permeation } \\
\text { - Conjugation of carrier surfaces }\end{array}$ \\
\hline & $\begin{array}{l}\text { Solid lipid } \\
\text { nanoparticles }\end{array}$ & $\begin{array}{l}\text { Tacrolimus (30) Betamethasone (68) Glucocorticoid } \\
\text { (67) Prednicarbate (70) }\end{array}$ & $\begin{array}{l}\text { - Phase interaction at the interfaces } \\
\text { - Controlled and Targeted drug delivery } \\
\text { - Protection of drug from environmental factors } \\
\text { - Prepared using biological lipids and without use of } \\
\text { organic solvents } \\
\text { - Improved bioavailability } \\
\text { - Carrier for lipophilic as well as hydrophilic drugs } \\
\text { - Improved stability }\end{array}$ \\
\hline & Metal & Silver (77) & $\begin{array}{l}\text { - Very useful in biomedical imaging } \\
\text { - Resistance against chemical/thermal denaturation } \\
\text { - Suitable for conjugation }\end{array}$ \\
\hline Liposome & & $\begin{array}{l}\text { Cyclosporine A (74) } \\
\text { Taxifolin } \\
\text { Glycoside-conjugated with Pep1 peptide (69) }\end{array}$ & $\begin{array}{l}\text { - No chemical modification is required to } \\
\text { incorporate hydrophobic and hydrophilic } \\
\text { compounds } \\
\text { - High durability } \\
\text { - Passive drug loading is possible } \\
\text { - Stays longer in circulation } \\
\text { - Easy surface functionalization }\end{array}$ \\
\hline \multicolumn{2}{|c|}{ Nanostructured lipid carrier } & $\begin{array}{l}\text { Tacrolimus (78), Fluticasone }(79,80) \text {, Betamethasone } \\
\text { dipropionate (81) }\end{array}$ & $\begin{array}{l}\text { - Incorporates drug in its highly unordered lipid } \\
\text { matrix } \\
\text { - Initial dose dumping can be achieved by providing } \\
\text { trigger impulse to matrix }\end{array}$ \\
\hline
\end{tabular}

atopic dermatitis. However, they have many limitations such as low drug loading capacity due to crystalline structure of lipid, polymorphic transition, and lipid particle growth in lipid-based systems (61) and for polymeric systems premature degradation of polymer, aggregation of toxic monomers and residual material associated with them (82).

Emerging formulations such as cubosomes, ethosomes, transferosomes, nanofibers, ionic liquids, nanosponge, and micelles are now being explored for topical drug delivery as the potential solution to the limitations associated with existing formulations. In this section, we have discussed emerging nanomaterials and their applicability in the topical drug delivery.

\section{Cubosomes}

Cubosomes are generally prepared using monoolein and are nanoparticle of lipid matrix having inter-crossing water channels with cubic phase and are effective carriers for dermal delivery (83). Liposomes and cubosomes have some common features which includes nano size, feasibility to incorporate water and oil soluble drugs, and they are made up of biocompatible lipids. They have a unique thermodynamic activity which enables loading of water-soluble drug in lipid carrier and as a result skin permeation is enhanced $(84,85)$.

Kwon and Kim (86) developed cubosomes of Houttuynia cordata (HC) to overcome the problem of low skin permeation. The main aim was to enhance the anti-atopic dermatitis effect of aqueous extract of HC (AEHC). AEHC containing cubosomal suspension of monoolein and liposomal suspension of egg phosphotidylcholine were prepared by a thin film hydration method. The skin permeations of AEHC containing cubosomes, lipososmes, and AEHC dissolved in PBS (phosphate buffer saline) were investigated by in vitro method using Franz diffusion cell-mounted hairless mouse skin. Furthermore, 1-chloro-2,4-dinitrobenzene (DNCB) was used to induce AD-like skin lesion in hairless mice and microscopical evaluation was performed to check the inhibitory effects of AEHC-containing formulations. Serum IgE 
level and cytokine expression were also noted. It was concluded that the cubosomal suspension containing AEHC would be effective treatment for AD.

\section{Ethosomes}

Ethosomes are made up of phospholipids and high concentration of water and alcohol. They are flexible and stable. They have the capability to penetrate stratum corneum and deliver therapeutic moiety into deep skin and/ or blood. It has been reported that ethosomes are safe, enhance drug efficiency, improve patient compliance, and display cost-effective treatment. The ethosomes can lead to dermatitis or skin irritation due the high ethanol concentration. Nevertheless, Paolini et al. (87) reported that ethosomes demonstrated better skin tolerability in human volunteers with $45 \%$ of ethanol in the formulation, for $48 \mathrm{~h}$. Additionally, ethanol is responsible for decrease in density of the lipid multilayer of cell membranes and elevate the fluidity of cell membrane lipids leading to improved skin permeability. Thus, it can penetrate to the deeper layers of the skin where they fuse with the lipids of the skin and release therapeutic moiety.

\section{Nanofibres}

Chitin nanofibril (CNF) application was explored as upcoming technology by Azuma et al. (88) on an experimental AD model. CNF showed the anti-inflammatory effects via activation of nuclear factor-kappa $\mathrm{B}$ and inducible nitric oxide synthase suppression. It may be concluded that CNF is a potential functional biomaterial for suppression of $\mathrm{AD}$.

\section{Transferosomes}

Transferosomes is commonly known as ultra-deformable liposomes and has lot of advantages over liposomes such as high vesicle deformability and elasticity and superior penetration capability. Thus, this system can be explored and can be suited for transdermal or/and dermal delivery with deliberate and controlled release of therapeutic moiety. It has been reported that transferosomes have an ability to transfer $0.1 \mathrm{mg}$ lipid per hour per $\mathrm{cm}^{2}$ area across undamaged skin, which is owing to the osmotic gradient generated by the difference in water content of the striatum corneum $(15 \%)$ and the viable epidermis (75\%). Furthermore, transferosomes have been proposed as a penetration enhancer facilitating entry of drugs through the stratum corneum by disruption of highly ordered lipid structure.

Lei et al. (89) developed tacrolimus-loaded transferosomes for the treatment of atopic dermatitis. Prepared transferosomes were compared with commercial ointment and liposomal gel of the tacrolimus. Surfactants like disodium cholate, Tween 80, and Span 80 were explored for the preparation of transferosomes, out of which Tween 80 showed best results for deformability and drug loading. Percentage entrapment was different with all the surfactants. Maximum entrapment into transferosomes was achieved with Span $80(83.88 \%)$. With Tween 80 and SDC, it was $(78.86 \%)$ and $(70.60 \%)$ respectively. Mean particle sizes of transferosomes were 135.6, 123.1, and $260.6 \mathrm{~nm}$ with SDC, Tween 80, and Span 80 respectively, where mean particle size of liposomes was $159.7 \mathrm{~nm}$. Transferosomes and other lipidbased vesicles can be differentiated by deformability. Transferosomes spontaneously deform without breaking the structure off lipid when stress is applied on vesicles to penetrate the skin pores. The achieved deformability of transferosomes was the 1.4-2.1 times higher than that of the liposomes and retention levels in skin was 1.2-1.6 times higher. Biphasic drug release was observed from transferosome gel and liposome gel, where initial burst release may be observed from the surface-adsorbed drug and the slower release may be from the lipid vesicles (90). The cumulative drug release after $24 \mathrm{~h}$ from transferosome gel, liposome gel, and ointment were (116.72-7.49) $\mu \mathrm{g}$, (95.75-5.89) $\mu \mathrm{g}$, and (41.34-3.59) $\mu \mathrm{g}$ respectively. In vivo experiments were performed using mice model of atopic dermatitis and the results from those experiments were in support of in vitro studies. Transferosome gel showed quicker effect than liposome gel and commercial ointment. Ear swelling was reduced, and skin pathology was also improved markedly. Hence, transferosomes can be considered as one of the useful carriers for dermal delivery to treat for atopic dermatitis.

\section{Ionic Liquids}

Ionic liquids (IL) are salts composed with relatively large asymmetric organic cations and inorganic or organic anions and having melting point lower than the boiling point of water. They have the capability to dissolve polymeric, organic, and inorganic materials and possess high thermal stability (91). ILs with specific physical or chemical properties can be synthesized by variation of alkyl chain length or cationic structure $(92,93)$. Since the past decade, ILs have gained interest to be explored in pharmaceutical applications as they have been found to be useful for solubility enhancement of the poorly soluble drugs $(94,95)$. Because of their property, ILs can be used for drug delivery via topical route as well.

Dobler et al. (96) explored the use of ionic liquids as different additives in the topical drug delivery system. They used hydrophilic IL [HMIM] [Cl] and the hydrophobic IL [BMIM] [PF6] for the preparation of oil-in-water $(\mathrm{O} / \mathrm{W})$ and water-in-oil $(\mathrm{W} / \mathrm{O})$ emulsions. Prepared formulations were evaluated for the influence of the ILs on emulsion properties. They found that formulations remain stable after incorporation of ILs into emulsion structure. Formulations showed good antimicrobial activity and preservation efficacy in the concentration range above $5 \%$. Overall, they found that ILs are safe and show improved penetration if used as carriers for topical drug delivery.

Mitragotri et al. (97) studied delivery of therapeutic RANi moieties robed with ionic liquid for treating the skin diseases. They showed that synthesis of robed siRNAs was a simple two-step process from bulk materials. Essential properties like skin transport, octanol water partitioning, and cell internalization for the dermal delivery of siRNA were tuneable with robing. They evaluated the safety and efficacy of robed siRNA by studying its potential to limit the breakdown of elastin in human skin tissues after UVB exposure. They concluded that therapeutic RNAi robed with 
ionic liquid moieties are a simple, scalable prodrug platform for treating skin disease.

\section{Nanosponge}

Iriventi et al. (98) developed a topical gel loaded with nanosponge of curcumin and caffeine. The formulation was prepared by hot melt method using dimethyl carbonate (DMC) as and beta-cyclodextrin $(\beta-C D)$ as crosslinker and polymer respectively. Curcumin- and caffeine-loaded nanosponge-based gel showed better therapeutic effect in comparison with the conventional marketed formulation. The aim behind the preparation of nanosponge and loading them in gel was to achieve sustained release of the drug and that was fulfilled as the formulation showed drug release up to 12 h. In vitro results were supported by in vivo studies and ex vivo permeation studies. It was concluded that nanosponge-loaded gel formulation has higher potential to alleviate psoriasis and thus can be explored for other skin diseases which involves inflammatory responses and may be proposed as a promising carrier for an effective local treatment.

Abbas et al. (99) explored fluconazole-loaded nanosponge-based hydrogel system for improved topical delivery. The prepared nanosponge was evaluated for their entrapment efficiency, particle size, structural properties, and in vitro drug release. Release pattern indicated the sustained release of fluconazole from hydrogel and showed Higuchi model as the best fit model. Key advantages of nanosponge are better retention, reduced systemic side effects and dosing frequency which makes it potentially suitable for the treatment and improve patient compliance.

\section{Micelles}

Assem et al. (100) developed polymeric micelles of beclomethasone dipropionate and incorporated them into biocompatible hydrogel. The formulation was evaluated using sub-chronic dermatitis animal model. Mixed micelles intended to target dermal delivery were prepared. Various concentrations of pluronic L121 were used with either poloxamer P84 or poloxamer 407. Micelles were incorporated into hydrogels and evaluated for viscosity and was also subjected to ex vivo skin permeation study in comparison with marketed cream Beclozone ${ }^{\circledR}$. In vivo studies were performed using rat model and results of histopathology of the skin showed that the prepared micelles are more effective in treating atopic dermatitis as compared to the Beclozone ${ }^{\circ}$. Hence, micelles can be considered as promising drug delivery in the treatment of skin diseases.

Lapteva et al. (101) developed polymeric micelles of Tacrolimus (FK506) for the treatment of psoriasis. Polymeric micelles were prepared using biodegradable and biocompatible methoxypoly(ethylene glycol)-dihexyl-substituted polylactide (MPEG-dihex-PLA) diblock copolymer and the results proved the efficiency of MPEG-dihexPLA micelles for the selective cutaneous delivery of FK506, superior to the marketed formulation (Protopic). Since the FK506 is prescribed for atopic dermatitis, this formulation can be explored for AD as well.
Although emerging nanomaterials are not widely explored for the treatment of atopic dermatitis, their potential for topical drug delivery is quite promising. Hence, they possess bright future to be explored for the treatment of AD.

\section{FUTURE OF AD USING NANOMEDICINE}

Nanomedicines are beneficial in achieving the desired rate of release and the skin targeting by modifying permeation and penetration of active substances. Improved retention in the skin ensures a drug localization in the stratum corneum and protection of drug against chemical or physical changes. Furthermore, maintenance of normal skin barrier function is essential while delivering the therapeutic agents. Use of chemical enhancers like surfactants and organic solvents may be responsible for reduction in the barrier function along with higher skin irritancy/damage.

Nanoparticle-based drug delivery systems is beneficial in overcoming the limitations and adverse effects of existing delivery system by enhancing the local effect. Researchers have a big challenge in front of them for identifying a suitable approach for exponential growth in $\mathrm{AD}$ and other skin diseases. Literature indicates enormous work explored by scientists on the potential use of antibiotics, corticosteroids, calcineurin inhibitors, and few natural polyphenolic compounds after suitable incorporation into carrier systems for effective treatment of AD. The research output is promising in treating $\mathrm{AD}$ effectively. However, there are few challenges like toxicity of the nanomedicines, dose determination, and cost effectiveness that are still to be resolved.

\section{CONCLUSION}

Nanomedicine is offering various opportunities in the field of research and business and it is representing the crucial technology development in the twenty-first century (102). There are many nanotechnology-based cosmeceutical products capturing the market and potential of products for AD is being proven at the research level. However, there are several emerging nanocarriers such as ionic liquids (103), silica nanoparticles (104), plant- and milk-based proteins, and silicon nanoparticles (105), which are already explored for oral delivery and holds enormous potential for topical delivery of peptides, proteins, and poorly soluble and permeable small molecules (106). Their untapped potential needs to be investigated in detail.

Nanomedicines have capability to minimize dosing frequency, achieve effective therapeutic concentration, reduce side effects, and improve patient compliance with targeted delivery of many drugs peptides and proteins. However, there is a great need for detailed investigation on the usefulness of NPs as substantial carrier for topical administration and its distribution in the skin particularly when used with the topical gel or cream. With the development of technology, there is wider scope for linkage between instruments and nanotechnology with greater understanding about easing off the skin diseases by establishing in vitro and in vivo correlation. However, future studies are still necessary to establish its safety and efficacy in order to ensure consumer health. 


\section{ACKNOWLEDGMENTS}

Authors are thankful to Institute of Pharmacy, Nirma University, for providing facilities and support. Authors would like to thank DST, SERB, CII, Government of India, and CSIR for providing financial assistances in the form of Prime Minister's Fellowship and CSIR-SRF Fellowship respectively to Khushali Parekh (D.O. No SERB/PM Fellow/CII-FICCI/Meeting/2018 dated 27/02/2018 and Namdev Dhas (09/1048(007)/2018-EMR-I. Dr. Popat would like to thank NHMRC for Early and Career Development Fellowship.

\section{COMPLIANCE WITH ETHICAL STANDARDS}

Conflict of Interest The authors declare that they have no conflict of interest.

\section{REFERENCES}

1. Kaltoft K, Pedersen CB, Hansen BH, Lemonidis AS, Frydenberg J, Thestrup-Pedersen K. In vitro genetically aberrant $\mathrm{T}$ cell clones with continuous growth are associated with atopic dermatitis. Arch Dermatol Res. 1994;287(1):42-7.

2. Lee H, Suh SS, Park E, Cho E, Ahn JH, Kim SG, et al. The AGAMOUS-LIKE 20 MADS domain protein integrates floral inductive pathways in Arabidopsis. Genes Dev. 2000;14(18):2366-76.

3. Vandita K, Manoj K, Komal S. An overview of atopic dermatitis with a focus on nano-interventions. EMJ Innov. 2019;3(1):44-54.

4. Gaspar NK, Aidé MK. Atopic dermatitis: allergic dermatitis or neuroimmune dermatitis? An Bras Dermatol. 2016;91(4):47988.

5. Thomsen SF. Atopic dermatitis: natural history, diagnosis, and treatment. ISRN Allergy. 2014;2014:1-7.

6. Eichenfield LF, Ellis CN, Mancini AJ, Paller AS, Simpson EL. Atopic dermatitis: epidemiology and pathogenesis update. Semin Cutan Med Surg. 2012;31(3):S3-5.

7. Nutten S. Atopic dermatitis: global epidemiology and risk factors. Ann Nutr Metab. 2015;66(1):8-16.

8. Karimkhani Aksut C, Dellavalle RP, Naghavi M. 181 Global skin disease morbidity and mortality: an update from the Global Burden of Disease Study 2013. J Invest Dermatol. 2017:137(5):S31.

9. Langan SM, Irvine $\mathrm{AD}$, Weidinger S. Atopic dermatitis. Lancet. 2020;396(10247):345-60.

10. DaVeiga SP. Epidemiology of atopic dermatitis: a review. Allergy Asthma Proc. 2012;33(3):227-34.

11. Asher MI, Montefort S, Björkstén B, Lai CK, Strachan DP, Weiland SK, et al. Worldwide time trends in the prevalence of symptoms of asthma, allergic rhinoconjunctivitis, and eczema in childhood: ISAAC Phases One and Three repeat multicountry cross-sectional surveys. Lancet. 2006;368(9537):733-43.

12. Williams HC. Atopic dermatitis. N Engl J Med. 2005;352(22):2314-24.

13. Dhar S, Kanwar AJ. Epidemiology and clinical pattern of atopic dermatitis in a North Indian pediatric population. Pediatr Dermatol. 1998;15(5):347-51.

14. Spergel JM. From atopic dermatitis to asthma: the atopic march. Ann Allergy. Asthma Immunol Off Publ Am Coll Allergy Asthma Immunol. 2010;105(2):99-106 quiz 107-9, 117.
15. Lowe AJ, Carlin JB, Bennett CM, Hosking CS, Abramson MJ, Hill DJ, et al. Do boys do the atopic march while girls dawdle? J Allergy Clin Immunol. 2008;121(5):1190-5.

16. Thomsen SF, Ulrik CS, Kyvik KO, Hjelmborg J. v B, Skadhauge LR, Steffensen I, et al. Importance of genetic factors in the etiology of atopic dermatitis: a twin study. Allergy Asthma Proc. 2007;28(5):535-9.

17. Thomsen SF. The contribution of twin studies to the understanding of the aetiology of asthma and atopic diseases. Eur Clin Respir J [Internet]. 2015 Sep 11 [cited 2019 Jul 15];2. Available from: https://www.ncbi.nlm.nih.gov/pmc/articles/ PMC4653279/

18. Ahn K, Kim BE, Kim J, Leung DY. Recent advances in atopic dermatitis. Curr Opin Immunol. 2020;66:14-21.

19. Eyerich K, Novak N. Immunology of atopic eczema: overcoming the Th1/Th2 paradigm. Allergy. 2013;68(8):974-82.

20. Palmer CNA, Irvine AD, Terron-Kwiatkowski A, Zhao Y, Liao H, Lee SP, et al. Common loss-of-function variants of the epidermal barrier protein filaggrin are a major predisposing factor for atopic dermatitis. Nat Genet. 2006;38(4):441-6.

21. Nakai K, Yoneda K, Maeda R, Munehiro A, Fujita N, Yokoi I, et al. Urinary biomarker of oxidative stress in patients with psoriasis vulgaris and atopic dermatitis. J Eur Acad Dermatol Venereol JEADV. 2009;23(12):1405-8.

22. Cork MJ, Robinson DA, Vasilopoulos Y, Ferguson A, Moustafa M, MacGowan A, et al. New perspectives on epidermal barrier dysfunction in atopic dermatitis: geneenvironment interactions. J Allergy Clin Immunol. 2006;118(1):3-21 quiz 22-3.

23. Elias PM, Hatano Y, Williams ML. Basis for the barrier abnormality in atopic dermatitis: outside-inside-outside pathogenic mechanisms. J Allergy Clin Immunol. 2008;121(6):133743.

24. Nemoto-Hasebe I, Akiyama M, Nomura T, Sandilands A, McLean WHI, Shimizu H. Clinical severity correlates with impaired barrier in filaggrin-related eczema. J Invest Dermatol. 2009;129(3):682-9.

25. Katoh N. Future perspectives in the treatment of atopic dermatitis. J Dermatol. 2009;36(7):367-76.

26. Katayama I, Aihara M, Ohya Y, Saeki H, Shimojo N, Shoji S, et al. Japanese guidelines for atopic dermatitis 2017. Allergol Int. 2017;66(2):230-47.

27. Leung DY, Harbeck R, Bina P, Reiser RF, Yang E, Norris DA, et al. Presence of IgE antibodies to staphylococcal exotoxins on the skin of patients with atopic dermatitis. Evidence for a new group of allergens. J Clin Invest. 1993;92(3):1374-80.

28. Scharschmidt TC, Segre JA. Modeling atopic dermatitis with increasingly complex mouse models. J Invest Dermatol. 2008;128(5):1061-4.

29. Bouwstra JA, de Graaff A, Gooris GS, Nijsse J, Wiechers JW, van Aelst AC. Water distribution and related morphology in human stratum corneum at different hydration levels. J Invest Dermatol. 2003;120(5):750-8.

30. Pople PV, Singh KK. Development and evaluation of colloidal modified nanolipid carrier: application to topical delivery of tacrolimus. Eur J Pharm Biopharm. 2011;79(1):82-94.

31. Snijders BEP, Thijs C, van Ree R, van den Brandt PA. Age at first introduction of cow milk products and other food products in relation to infant atopic manifestations in the first 2 years of life: the KOALA Birth Cohort Study. Pediatrics. 2008;122(1):e115-22.

32. Dunlop AL, Reichrtova E, Palcovicova L, Ciznar P, Adamcakova-Dodd A, Smith SJ, et al. Environmental and dietary risk factors for infantile atopic eczema among a Slovak birth cohort. Pediatr Allergy Immunol Off Publ Eur Soc Pediatr Allergy Immunol. 2006;17(2):103-11.

33. Rowlands D, Tofte SJ, Hanifin JM. Does food allergy cause atopic dermatitis? Food challenge testing to dissociate eczematous from immediate reactions. Dermatol Ther. 2006;19(2):97-103.

34. Akdis CA, Akdis M, Bieber T, Bindslev-Jensen C, Boguniewicz M, Eigenmann P, et al. Diagnosis and treatment of atopic dermatitis in children and adults: European Academy of Allergology and Clinical Immunology/American Academy of Allergy, Asthma and Immunology/PRACTALL 
Consensus Report. J Allergy Clin Immunol. 2006;118(1):15269.

35. Saeki H, Furue M, Furukawa F, Hide M, Ohtsuki M, Katayama I, et al. Guidelines for management of atopic dermatitis. J Dermatol. 2009;36(10):563-77.

36. Katoh N, Hirano S, Kishimoto S. Prognostic factor of adult patients with atopic dermatitis. J Dermatol. 2008;35(8):477-83.

37. Drugs@FDA: FDA Approved Drug Products [Internet]. [cited 2019 Jul 18]. Available from: https://www.accessdata.fda.gov/ scripts/cder/daf/

38. Ellis CN, Mancini AJ, Paller AS, Simpson EL, Eichenfield LF. Understanding and managing atopic dermatitis in adult patients. Semin Cutan Med Surg. 2012;31(3):S18-22.

39. Home - ClinicalTrials.gov [Internet]. [cited 2020 Aug 9]. Available from: https://clinicaltrials.gov/

40. Coondoo A, Phiske M, Verma S, Lahiri K. Side-effects of topical steroids: a long overdue revisit. Indian Dermatol Online J. 2014;5(4):416-25.

41. Yamamoto T, Matsunaga T, Nishioka K. Rheumatoid neutrophilic dermatitis, rheumatoid papules, and rheumatoid nodules in a patient with seronegative rheumatoid arthritis. J Am Acad Dermatol. 2003;48(4):634-5.

42. Patel A, Patel M, Yang X, Mitra AK. Recent advances in protein and peptide drug delivery: a special emphasis on polymeric nanoparticles. Protein Pept Lett. 2014;21(11):110220.

43. Mocan T, Matea CT, Iancu C, Agoston-Coldea L, Mocan L, Orasan R. Hypersensitivity and nanoparticles: update and research trends. Clujul Med. 2016;89(2):216-9.

44. Iqbal MA, Md S, Sahni JK, Baboota S, Dang S, Ali J. Nanostructured lipid carriers system: recent advances in drug delivery. J Drug Target. 2012;20(10):813-30.

45. Nastiti CMRR, Ponto T, Abd E, Grice JE, Benson HAE, Roberts MS. Topical nano and microemulsions for skin delivery. Pharmaceutics [Internet]. 2017 Sep 21 [cited 2020 Sep 7];9(4). Available from: https://www.ncbi.nlm.nih.gov/pmc/ articles/PMC5750643/

46. Charman WN, Stella VJ. Transport of lipophilic molecules by the intestinal lymphatic system. Adv Drug Deliv Rev. 1991;7(1):1-14.

47. Karuppagounder V, Arumugam S, Thandavarayan RA, Sreedhar R, Giridharan VV, Watanabe K. Molecular targets of quercetin with anti-inflammatory properties in atopic dermatitis. Drug Discov Today. 2016;21(4):632-9.

48. Zeb A, Arif ST, Malik M, Shah FA, Din FU, Qureshi OS, et al. Potential of nanoparticulate carriers for improved drug delivery via skin. J Pharm Investig. 2019;49(5):485-517.

49. Zhuo F, Abourehab MAS, Hussain Z. Hyaluronic acid decorated tacrolimus-loaded nanoparticles: efficient approach to maximize dermal targeting and anti-dermatitis efficacy. Carbohydr Polym. 2018;197:478-89.

50. Pandey M, Choudhury H, Gunasegaran TAP, Nathan SS, Md S, Gorain B, et al. Hyaluronic acid-modified betamethasone encapsulated polymeric nanoparticles: fabrication, characterisation, in vitro release kinetics, and dermal targeting. Drug Deliv Transl Res. 2019;9(2):520-33.

51. Try C, Moulari B, Béduneau A, Fantini O, Pin D, Pellequer Y, et al. Size dependent skin penetration of nanoparticles in murine and porcine dermatitis models. Eur J Pharm Biopharm. 2016;100:101-8.

52. Siddique MI, Katas H, Jamil A, Mohd Amin MCI, Ng S-F, Zulfakar MH, et al. Potential treatment of atopic dermatitis: tolerability and safety of cream containing nanoparticles loaded with hydrocortisone and hydroxytyrosol in human subjects. Drug Deliv Transl Res. 2019;9(2):469-81.

53. Sahle FF, Gerecke C, Kleuser B, Bodmeier R. Formulation and comparative in vitro evaluation of various dexamethasoneloaded $\mathrm{pH}$-sensitive polymeric nanoparticles intended for dermal applications. Int J Pharm. 2017;516(1-2):21-31.

54. Fessi H, Puisieux F, Devissaguet JP, Ammoury N, Benita S. Nanocapsule formation by interfacial polymer deposition following solvent displacement. Int J Pharm. 1989;55(1):R1-4.

55. Katas H, Hussain Z, Ling TC. Chitosan nanoparticles as a percutaneous drug delivery system for hydrocortisone. J Nanomater. 2012;2012:372725.
56. Yu K, Wang Y, Wan T, Zhai Y, Cao S, Ruan W, et al. Tacrolimus nanoparticles based on chitosan combined with nicotinamide: enhancing percutaneous delivery and treatment efficacy for atopic dermatitis and reducing dose. Int $\mathbf{J}$ Nanomedicine. 2017;13:129-42.

57. Ghosh N, Mitra S, Banerjee ER. Therapeutic effects of topically-administered guar gum nanoparticles in oxazoloneinduced atopic dermatitis in mice. Biomedical Research and Therapy. 5(5):2305-25. https://doi.org/10.15419/bmrat.v5i5.444.

58. Rosado C, Silva C, Reis CP. Hydrocortisone-loaded poly( $\varepsilon$ caprolactone) nanoparticles for atopic dermatitis treatment. Pharm Dev Technol. 2013;18(3):710-8.

59. Pople PV, Singh KK. Targeting tacrolimus to deeper layers of skin with improved safety for treatment of atopic dermatitis-Part II: In vivo assessment of dermatopharmacokinetics, biodistribution and efficacy. Int $\mathbf{J}$ Pharm. 2012;434(1-2):70-9.

60. Das S, Ng WK, Tan RBH. Are nanostructured lipid carriers (NLCs) better than solid lipid nanoparticles (SLNs): development, characterizations and comparative evaluations of clotrimazole-loaded SLNs and NLCs? Eur J Pharm Sci Off J Eur Fed Pharm Sci. 2012;47(1):139-51.

61. Naseri N, Valizadeh H, Zakeri-Milani P. Solid lipid nanoparticles and nanostructured lipid carriers: structure, preparation and application. Adv Pharm Bull. 2015;5(3):305-13.

62. Müller RH, Radtke M, Wissing SA. Nanostructured lipid matrices for improved microencapsulation of drugs. Int $\mathbf{J}$ Pharm. 2002;242(1):121-8

63. Tapeinos C, Battaglini M, Ciofani G. Advances in the design of solid lipid nanoparticles and nanostructured lipid carriers for targeting brain diseases. J Control Release. 2017;264:306-32.

64. Chauhan I, Yasir M, Verma M, Singh AP. nanostructured lipid carriers: a groundbreaking approach for transdermal drug delivery. Adv Pharm Bull. 2020;10(2):150-65.

65. Siddique MI, Katas H, Amin MCIM, Ng S-F, Zulfakar MH, Jamil A. In-vivo dermal pharmacokinetics, efficacy, and safety of skin targeting nanoparticles for corticosteroid treatment of atopic dermatitis. Int J Pharm. 2016;507(1-2):72-82.

66. Pople PV, Singh KK. Development and evaluation of colloidal modified nanolipid carrier: Application to topical delivery of tacrolimus, Part II - In vivo assessment, drug targeting, efficacy, and safety in treatment for atopic dermatitis. Eur J Pharm Biopharm. 2013;84(1):72-83.

67. Maia CS, Mehnert W, Schäfer-Korting M. Solid lipid nanoparticles as drug carriers for topical glucocorticoids. Int J Pharm. 2000;196(2):165-7.

68. Kong X, Zhao Y, Quan P, Fang L. Development of a topical ointment of betamethasone dipropionate loaded nanostructured lipid carrier. Asian J Pharm Sci. 2016;11(2):248-54.

69. Kang MJ, Eum JY, Park SH, Kang MH, Park KH, Choi SE, et al. Pep-1 peptide-conjugated elastic liposomal formulation of taxifolin glycoside for the treatment of atopic dermatitis in NC/Nga mice. Int J Pharm. 2010;402(1-2):198-204.

70. Baspinar Y, Keck CM, Borchert H-H. Development of a positively charged prednicarbate nanoemulsion. Int J Pharm. 2010;383(1-2):201-8.

71. Lalan MS, Laddha NC, Lalani J, Imran MJ, Begum R, Misra A. Suppression of cytokine gene expression and improved therapeutic efficacy of microemulsion-based tacrolimus cream for atopic dermatitis. Drug Deliv Transl Res. 2012;2(2):129-41.

72. Sarfaraz Alam M, Ali MS, Zakir F, Alam N, Intakhab Alam M, Ahmad F, et al. Enhancement of anti-dermatitis potential of clobetasol propionate by DHA [docosahexaenoic acid] rich algal oil nanoemulsion gel. Iran J Pharm Res IJPR. 2016;15(1):35-52.

73. Yang M, Gu Y, Yang D, Tang X, Liu J. Development of triptolide-nanoemulsion gels for percutaneous administration: physicochemical, transport, pharmacokinetic and pharmacodynamic characteristics. J Nanobiotechnology. 2017;15(1):88.

74. Romero GB, Arntjen A, Keck CM, Müller RH. Amorphous cyclosporin A nanoparticles for enhanced dermal bioavailability. Int J Pharm. 2016;498(1-2):217-24.

75. Lohan SB, Saeidpour S, Colombo M, Staufenbiel S, Unbehauen M, Wolde-Kidan A, et al. Nanocrystals for 
improved drug delivery of dexamethasone in skin investigated by EPR spectroscopy. Pharmaceutics. 2020;12(5):400.

76. Haeri A, Osouli M, Bayat F, Alavi S, Dadashzadeh S. Nanomedicine approaches for sirolimus delivery: a review of pharmaceutical properties and preclinical studies. Artif Cells Nanomedicine Biotechnol. 2018;46(sup1):1-14.

77. $\mathrm{Cm} \mathrm{K}, \mathrm{K}$ S. Silver-nanolipid complex for application to atopic dermatitis skin: rheological characterization, in vivo efficiency and theory of action. Vol. 5, Journal of biomedical nanotechnology. J Biomed Nanotechnol; 2009.

78. Nam S-H, Ji XY, Park J-S. Investigation of tacrolimus loaded nanostructured lipid carriers for topical drug delivery. Bull Kor Chem Soc. 2011;32(3):956-60.

79. Doktorovová S, Araújo J, Garcia ML, Rakovský E, Souto EB. Formulating fluticasone propionate in novel PEG-containing nanostructured lipid carriers (PEG-NLC). Colloids Surf B: Biointerfaces. 2010;75(2):538-42.

80. Doktorovová S, Kovačević AB, Garcia ML, Souto EB Preclinical safety of solid lipid nanoparticles and nanostructured lipid carriers: current evidence from in vitro and in vivo evaluation. Eur J Pharm Biopharm Off J Arbeitsgemeinschaft Pharm Verfahrenstechnik EV. 2016;108:235-52.

81. $\mathrm{Pa} \mathrm{H}, \mathrm{Mm}$ G. S G. Development of betamethasone dipropionate-loaded nanostructured lipid carriers for topical and transdermal delivery. Anti-Inflamm Anti-Allergy Agents Med Chem. 2019;18(1):26-44.

82. Lockman PR, Mumper RJ, Khan MA, Allen DD. Nanoparticle technology for drug delivery across the blood-brain barrier. Drug Dev Ind Pharm. 2002;28(1):1-13.

83. Esposito E, Cortesi R, Drechsler M, Paccamiccio L, Mariani P, Contado $\mathrm{C}$, et al. Cubosome dispersions as delivery systems for percutaneous administration of indomethacin. Pharm Res. 2005;22(12):2163-73.

84. Sinico C, Manconi M, Peppi M, Lai F, Valenti D, Fadda AM. Liposomes as carriers for dermal delivery of tretinoin: in vitro evaluation of drug permeation and vesicle-skin interaction. $\mathrm{J}$ Control Release. 2005;103(1):123-36.

85. Taek-Kwan Kwon, Hyeon-Yong Lee, Jin-Chul Kim \& Baik Hwang. In vitro skin permeation enhancement of asiaticoside by liquid crystal vesicles. Molecular Crystals and Liquid Crystals, 508:1, 191/[553]-199/[561], https://doi.org/10.1080/ 15421400903060847.

86. Kwon TK, Kim J-C. In vitro skin permeation and anti-atopic efficacy of lipid nanocarriers containing water soluble extracts of Houttuynia cordata. Drug Dev Ind Pharm. 2014;40(10):1350-7.

87. Paolino D, Celia C, Trapasso E, Cilurzo F, Fresta M. Paclitaxel-loaded ethosomes ${ }^{\circledR}$ : Potential treatment of squamous cell carcinoma, a malignant transformation of actinic keratoses. Eur J Pharm Biopharm. 2012;81(1):102-12.

88. Izumi R, Azuma K, Izawa H, Morimoto M, Nagashima M, Osaki T, et al. Chitin nanofibrils suppress skin inflammation in atopic dermatitis-like skin lesions in $\mathrm{NC} / \mathrm{Nga}$ mice. Carbohydr Polym. 2016;146:320-7.

89. Laouini A, Jaafar-Maalej C, Sfar S, Charcosset C, Fessi H. Liposome preparation using a hollow fiber membrane contactor-application to spironolactone encapsulation. Int $\mathrm{J}$ Pharm. 2011;415(1):53-61.

90. Lei W, Yu C, Lin H, Zhou X. Development of tacrolimusloaded transfersomes for deeper skin penetration enhancement and therapeutic effect improvement in vivo. Asian J Pharm Sci. 2013;8(6):336-45.

91. Huddleston JG, Visser AE, Reichert WM, Willauer HD, Broker GA, Rogers RD. Characterization and comparison of hydrophilic and hydrophobic room temperature ionic liquids incorporating the imidazolium cation. Green Chem. 2001;3(4):156-64.

92. Tokuda H, Hayamizu K, Ishii K. Susan MdABH, Watanabe M. Physicochemical properties and structures of room temperature ionic liquids. 2. Variation of alkyl chain length in imidazolium cation. J Phys Chem B. 2005;109(13):6103-10.

93. Tokuda H, Ishii K. Susan MdABH, Tsuzuki S, Hayamizu K, Watanabe M. Physicochemical properties and structures of room-temperature ionic liquids. 3. Variation of cationic structures. J Phys Chem B. 2006;110(6):2833-9.

94. Jaitely V, Karatas A, Florence AT. Water-immiscible room temperature ionic liquids (RTILs) as drug reservoirs for controlled release. Int J Pharm. 2008;354(1-2):168-73.

95. Mizuuchi H, Jaitely V, Murdan S, Florence AT. Room temperature ionic liquids and their mixtures: potential pharmaceutical solvents. Eur J Pharm Sci. 2008;33(4):326-31.

96. Dobler D, Schmidts T, Klingenhöfer I, Runkel F. Ionic liquids as ingredients in topical drug delivery systems. Int J Pharm. 2013;441(1-2):620-7.

97. Zakrewsky M, Mitragotri S. Therapeutic RNAi robed with ionic liquid moieties as a simple, scalable prodrug platform for treating skin disease. J Control Release. 2016;242:80-8.

98. Iriventi P, Gupta NV, Osmani RAM, Balamuralidhara V. Design \& development of nanosponge loaded topical gel of curcumin and caffeine mixture for augmented treatment of psoriasis. DARU J Pharm Sci. 2020 May 29.

99. Abbas N, Parveen K, Hussain A, Latif S, Uz Zaman S, Shah PA, et al. Nanosponge-based hydrogel preparation of fluconazole for improved topical delivery. Trop J Pharm Res. 2019;18(2):215.

100. Assem M, Khowessah OM, Ghorab D. Optimization and evaluation of beclomethasone dipropionate micelles incorporated into biocompatible hydrogel using a sub-chronic dermatitis animal model. AAPS PharmSciTech. 2019;20(4).

101. Lapteva M, Mondon K, Möller M, Gurny R, Kalia YN. polymeric micelle nanocarriers for the cutaneous delivery of tacrolimus: a targeted approach for the treatment of psoriasis. Mol Pharm. 2014;11(9):2989-3001.

102. Martins JP. das Neves J, de la Fuente M, Celia C, Florindo H, Günday-Türeli N, et al. The solid progress of nanomedicine. Drug Deliv Transl Res. 2020;10(3):726-9.

103. Dharamdasani V, Mandal A, Qi QM, Suzuki I, Bentley MVLB, Mitragotri S. Topical delivery of siRNA into skin using ionic liquids. J Control Release. 2020;323:475-82.

104. Abeer MM, Rewatkar P, Qu Z, Talekar M, Kleitz F, Schmid R, et al. Silica nanoparticles: a promising platform for enhanced oral delivery of macromolecules. J Control Release. 2020;326:544-55.

105. Pujara N, Wong KY, Qu Z, Wang R, Moniruzzaman Md, Rewatkar P, et al. Oral delivery of $\beta$-lactoglobulin-nanosphereencapsulated resveratrol alleviates inflammation in winnie mice with spontaneous ulcerative colitis. Mol Pharm. 2020.

106. Ndayishimiye J, Popat A, Blaskovich M, Falconer JR. Formulation technologies and advances for oral delivery of novel nitroimidazoles and antimicrobial peptides. J Control Release. 2020;324:728-49.

Publisher's Note Springer Nature remains neutral with regard to jurisdictional claims in published maps and institutional affiliations. 